\title{
Neutron Diffraction Study of $\mathrm{Pb}_{2} \mathrm{Sr}_{2} \mathrm{HoCu}_{3} \mathrm{O}_{8}$
}

\author{
J.-E. Jørgensen ${ }^{a}$ and N. H. Andersen ${ }^{b}$ \\ ${ }^{a}$ Department of Chemistry, Aarhus University, DK-8000 Aarhus C and ${ }^{\mathrm{b}}$ Risø National Laboratory, P.O. Box 49, DK-4000 Roskilde, \\ Denmark
}

\begin{abstract}
Jørgensen, J.-E. and Andersen, N. H., 1991. Neutron Diffraction Study of $\mathrm{Pb}_{2} \mathrm{Sr}_{2} \mathrm{Ho}$ $\mathrm{Cu}_{3} \mathrm{O}_{8}$. - Acta Chem. Scand. 45: 19-22.

The title compound has been studied by neutron and $\mathrm{X}$-ray diffraction. The overall symmetry was determined to be orthorhombic with lattice constants $a=5.378(3)$, $b=5.421(3)$ and $c=15.688(7) \AA$. Initial Rietveld refinements of the powder neutron data made in space group $\mathrm{Cmmm}$ showed that the oxygen atoms in the PbO layer are displaced from the $4 k(00 z)$ position. The final refinements were therefore done in space group $P 1$, with all atoms except the oxygen atoms in the $\mathrm{PbO}$ layer constrained to obey $C$-centering. The origin of the orthorhombic distortion of the unit cell was in this way found to be the distortion of the oxygen atoms in the $\mathrm{PbO}$ layer.
\end{abstract}

Recently a new class of high temperature superconductors with formula $\mathrm{Pb}_{2} \mathrm{Sr}_{2} \mathrm{Ln}_{1-x} \mathrm{~A}_{x} \mathrm{Cu}_{3} \mathrm{O}_{8}$ where $\mathrm{Ln}$ is a lanthanide and $\mathrm{A}$ is $\mathrm{Ca}$ or $\mathrm{Sr}$ were discovered by Cava et al. ${ }^{1}$ Critical temperatures close to $70 \mathrm{~K}$ were reported for $\mathrm{Pb}_{2} \mathrm{Sr}_{2}$ $\mathrm{Y}_{1-x} \mathrm{Ca}_{x} \mathrm{Cu}_{3} \mathrm{O}_{8}$. These new materials have a sandwich construction of corner-shared $\mathrm{CuO}_{5}$ pyramids with rare-earth atoms located between the $\mathrm{CuO}_{5}$ pyramids. Furthermore, they contain a layer of $\mathrm{Cu}$ atoms linearly coordinated to oxygen atoms. A similar structural arrangement is found in $\mathrm{YBa}_{2} \mathrm{Cu}_{3} \mathrm{O}_{6}$. The stacking sequence in these compounds is $\mathrm{Ln}-\mathrm{CuO}_{2}-\mathrm{SrO}-\mathrm{PbO}-\mathrm{Cu}-\mathrm{PbO}-\mathrm{SrO}-\mathrm{CuO}_{2}-$. The $\mathrm{CuO}_{2}$ layers, which are believed to be of importance for superconductivity in high- $T_{\mathrm{c}}$ materials, are in these materials more separated than in, e.g., $\mathrm{YBa}_{2} \mathrm{Cu}_{3} \mathrm{O}_{7}$. It is therefore to be expected that they will show properties which are even more anisotropic than those of other high- $T_{\mathrm{c}}$ materials.

A single-crystal X-ray diffractions study of $\mathrm{Pb}_{2} \mathrm{Sr}_{2.24} \mathrm{Nd}_{0.76} \mathrm{Cu}_{3} \mathrm{O}_{8}$ showed that this compound is slightly orthorhombic $(a / b=0.995) .{ }^{1}$ The structure was refined in space group $\mathrm{Cmmm}$. The temperature factor for the oxygen atoms in the PbO layer was found to be abnormally large. The goal of the present powder neutron diffraction study was to determine the oxygen positions with higher accuracy and in this way hopefully explain the orthorhombic distortion of these compounds.

\section{Experimental}

The sample was prepared by firing a precursor of composition $\mathrm{Sr}_{2} \mathrm{HoCu}_{3} \mathrm{O}_{6.5}$ for $16 \mathrm{~h}$ at $980^{\circ} \mathrm{C}$ in air. The precursor was mixed with $\mathrm{PbO}$ in the stochiometric ratio and pressed into pellets. The pellets were reacted in air for $1 \mathrm{~h}$ at $885^{\circ} \mathrm{C}$ and rapidly cooled to room temperature. The sample was metallic but turned out to be non-superconducting. The lattice constants were determined from an X-ray Guinier film with Si as internal standard. All lines could be indexed on a $C$-centered orthorhombic cell with $a=5.378(3)$, $b=5.421(3)$ and $c=15.688(7) \AA$. The powder neutron diffraction experiment was performed on the multidetector powder diffractometer at the Ris $\varnothing$ National Laboratory. Data were collected at room temperature, and the 511 reflexion from the Ge monochromator crystal was used to produce a monochromatic neutron beam of wavelength $1.482 \AA$. The directions of the incident and scattered beams were defined by Soller collimators of angular divergence $10 \mathrm{~min}$ of arc. The following neutron scattering lengths were used in the calculations $b(\mathrm{~Pb})=0.9401$, $b(\mathrm{Sr})=0.702, b(\mathrm{Ho})=0.808, b(\mathrm{Cu})=0.7718, b(\mathrm{O})=$ $0.5805 \times 10^{-12} \mathrm{~cm}$. The Rietveld analysis was performed by using the program by Wiles and Young ${ }^{2}$ (version DBW $3.2 \mathrm{~S})$.

\section{Results and discussion}

The neutron data were analysed by Rietveld refinements of several models. The first refinements were made in the space group $\mathrm{Cmmm}$ with all atoms in the special positions used in Ref. 1. The oxygen atoms in the PbO layers la-

Table 1. Structural parameters for $\mathrm{Pb}_{2} \mathrm{Sr}_{2} \mathrm{HoCu}_{3} \mathrm{O}_{8}{ }^{a}$

\begin{tabular}{|c|c|c|c|c|c|c|}
\hline Atom & $x$ & $y$ & $z$ & $B / \AA^{2}$ & & \\
\hline $\mathrm{Pb}$ & 0.5 & 0.0 & $0.3878(3)$ & $0.61(8)$ & 41 & $m m$ \\
\hline $\mathrm{Sr}$ & 0.0 & 0.0 & $0.2234(3)$ & $0.19(7)$ & $4 k$ & $m m$ \\
\hline Ho & 0.0 & 0.0 & 0.0 & $0.19(7)$ & $2 a$ & $\mathrm{mmm}$ \\
\hline $\mathrm{Cu}(1)$ & 0.0 & 0.0 & 0.5 & $1.0(1)$ & $2 d$ & $\mathrm{mmm}$ \\
\hline $\mathrm{Cu}(2)$ & 0.5 & 0.0 & $0.1073(3)$ & $0.4(1)$ & 41 & $m m$ \\
\hline$O(1)$ & 0.5 & 0.0 & $0.2521(5)$ & $1.0(1)$ & 41 & $m m$ \\
\hline$O(3)$ & 0.25 & 0.25 & $0.0920(3)$ & $1.0(1)$ & $8 m$ & 2 \\
\hline \multicolumn{7}{|c|}{------------------------------1} \\
\hline $\mathrm{O}(2)$ & $0.069(6)$ & $0.102(7)$ & $0.386(2)$ & $0.8(3)$ & $2 i$ & 1 \\
\hline $\mathrm{O}\left(2^{\prime}\right)$ & $0.539(7)$ & $0.442(5)$ & $0.378(2)$ & $0.8(3)$ & $2 i$ & 1 \\
\hline
\end{tabular}

${ }^{a}\left(R_{\mathrm{w}}=10.19 \% ; R_{\mathrm{exp}}=4.57 \%\right)$ Atomic positions above dashed line have space group $\mathrm{Cmmm}$ symmetry, those below dashed line have space group $P \overline{1}$ symmetry. 


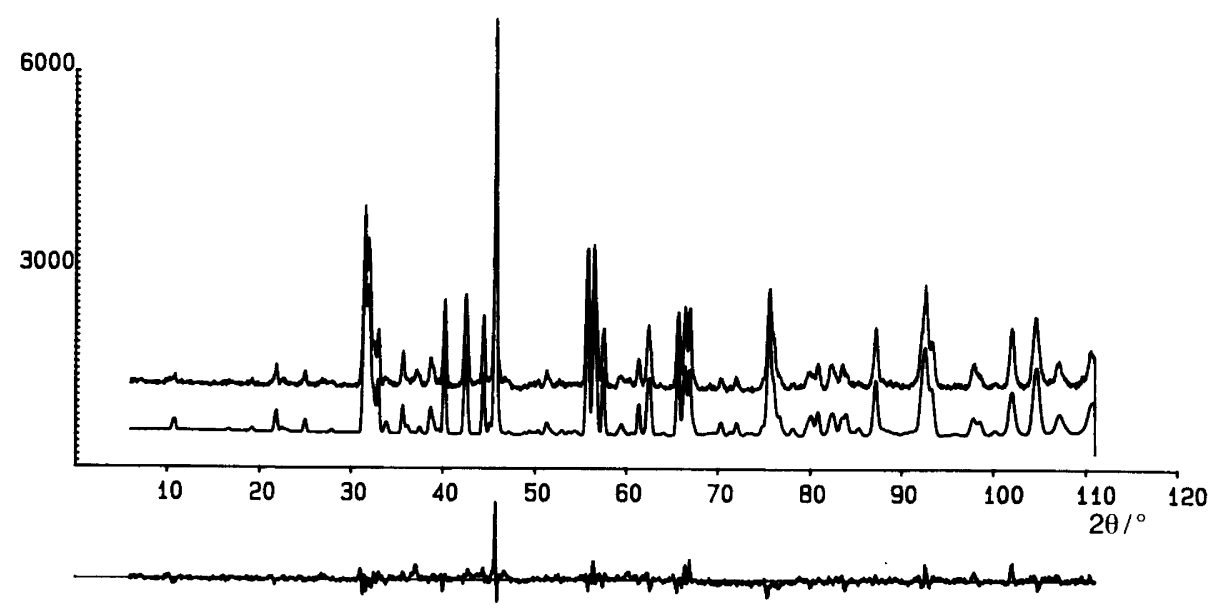

Fig. 1. Measured and calculated neutron diffraction profiles. The difference between observed and measured intensities is shown below.

belled $\mathrm{O}(2)$ are in the $4 k(00 z)$ position in this model. Refinements of this model yielded a temperature factor of $8.1 \AA^{2}$ for the $\mathrm{O}(2)$ atoms, which is much too large. A model in which the temperature factor for $\mathrm{O}(2)$ was refined anisotropically yielded large vibrational amplitudes in the $a$ and $b$ directions. The vibrational amplitude in the $b$ direction was the largest. and it was therefore decided to try a

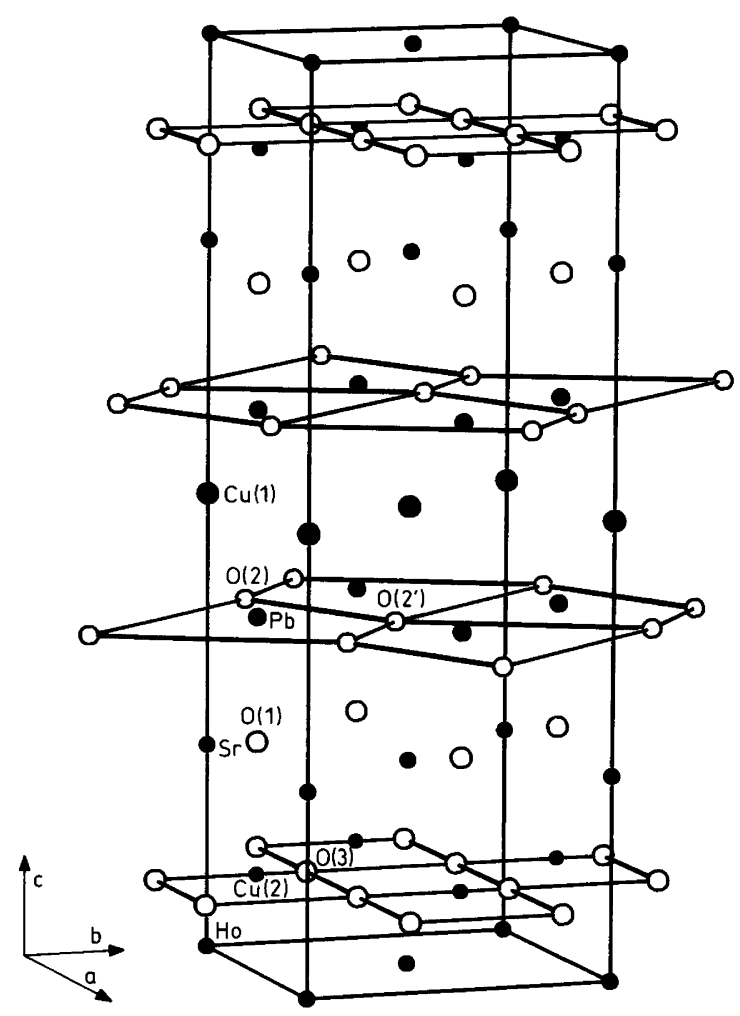

Fig. 2. Unit cell of $\mathrm{Pb}_{2} \mathrm{Sr}_{2} \mathrm{HoCu}_{3} \mathrm{O}_{8}$. Cations are marked with filled circles, oxygen atoms with open circles. The oxygenoxygen connections are marked in the $\mathrm{CuO}_{2}$ and $\mathrm{PbO}$ layers. These layers contain the $O(3), O(2)$ and $O\left(2^{\prime}\right)$ atoms, respectively. $\mathrm{O}(1)$ is located in the $\mathrm{SrO}$ layers. The $\mathrm{Cu}^{+}$ions labelled $\mathrm{Cu}(1)$ are located in the Cu layer. All atoms except the oxygen atoms in the $\mathrm{PbO}$ layer obey $C$-centering. model in which $\mathrm{O}(2)$ was placed in the $8 n(0 y z)$ position. Refinements of this model did not give a reasonable temperature factor for $\mathrm{O}(2)$ either. The $b$-value for $(\mathrm{O}) 2$ was $4 \AA^{2}$, and the agreement factors were $R_{\mathrm{w}}=10.77$ and $R_{\text {exp }}=4.57$ for this model. These results indicate either that $\mathrm{O}(2)$ is statistically disordered around the $4 k$ position or that the true symmetry is lower than orthorhombic. Weak reflexions violating $C$-centering have been observed by electron diffraction in other members of this family of compounds. ${ }^{1.3}$ Although the Guinier data gave no indication of symmetry lower than orthorhombic it was decided to try refinements in a space group of lower symmetry. The final refinements were done in the $P \overline{1}$ space group. All atoms except the $O(2)$ atoms were constrained to obey $C$-centering and placed in positions corresponding to their positions in the $\mathrm{Cmmm}$ space group. The violation of the $C$-centering by the $\mathrm{O}(2)$ atoms introduces two crystallographically independent atoms which in the following will be labelled $O(2)$ and $O\left(2^{\prime}\right)$. The angles of the unit cell were fixed at $90^{\circ}$ in the refinements. The temperature factors for Ho and Sr were constrained to have the same value, because initial refinements gave a negative temperature factor for Ho. Isotropic temperature factors were refined independently for the other groups of equivalent atoms. The results of the refinement is given in Table 1, and the observed and calculated profiles are shown in Fig. 1. The corresponding unit cell is shown in Fig. 2. The relevant interatomic distances are given in Table 2. As seen from Table 2 the $O(2)$ and $O\left(2^{\prime}\right)$ atoms have moved away from the $(00 z)$ and $(1 / 21 / 2 z)$ positions. Fig. 3 shows the connectivity and interatomic distances in the $\mathrm{PbO}$ and $\mathrm{CuO}_{2}$ layers. The $\mathrm{Pb}$ atoms are five-coordinated, with three short and two longer $\mathrm{Pb}-\mathrm{O}$ bonds. The short $\mathrm{Pb}-\mathrm{O}$ bonds lie in the range $2.129-2.50 \AA$, while the longer $\mathrm{Pb}-\mathrm{O}$ bonds lie in the range 2.92-3.29 $\AA$. Calculation of the valency of lead according to Brown and Altermatt ${ }^{4}$ gives 2.16, which shows that the proposed coordination around lead is reasonable. The "lone pair" of electrons on $\mathrm{Pb}^{2+}$ points along the perpendicular to the triangle formed by the three nearestneighbour oxygen atoms, and in this way points towards the $\mathrm{Cu}$ layer. The coordination of $\mathrm{Pb}$ is similar to that 
Table 2. Interatomic distances in $\mathrm{Pb}_{2} \mathrm{Sr}_{2} \mathrm{HoCu}_{3} \mathrm{O}_{8}$ (in $\AA$ ). ${ }^{a}$

\begin{tabular}{lll}
\hline $\mathrm{Pb}-\mathrm{O}(1)$ & $2.129(9)$ & $\times 1$ \\
$\mathrm{~Pb}-\mathrm{O}(2)$ & $2.39(4)$ & $\times 1$ \\
$\mathrm{~Pb}-\mathrm{O}\left(2^{\prime}\right)$ & $2.41(3)$ & $\times 1$ \\
$\mathrm{~Pb}-\mathrm{O}(2)$ & $3.11(3)$ & $\times 1$ \\
$\mathrm{~Pb}-\mathrm{O}\left(2^{\prime}\right)$ & $3.03(3)$ & $\times 1$ \\
$\mathrm{~Pb}-\mathrm{O}(1)$ & $2.129(9)$ & $\times 1$ \\
$\mathrm{~Pb}^{\prime}-\mathrm{O}(2)$ & $2.19(4)$ & $\times 1$ \\
$\mathrm{~Pb}-\mathrm{O}\left(2^{\prime}\right)$ & $2.92(3)$ & $\times 1$ \\
$\mathrm{~Pb}-\mathrm{O}(2)$ & $3.29(4)$ & $\times 1$ \\
$\mathrm{~Pb}-\mathrm{O}\left(2^{\prime}\right)$ & $2.50(4)$ & $\times 1$ \\
$\mathrm{Sr}-\mathrm{O}(1)$ & $2.726(2)$ & $\times 2$ \\
$\mathrm{Sr}-\mathrm{O}(1)$ & $2.748(2)$ & $\times 2$ \\
$\mathrm{Sr}-\mathrm{O}(2)$ & $2.63(3)$ & $\times 1$ \\
$\mathrm{Sr}-\mathrm{O}\left(2^{\prime}\right)$ & $2.46(3)$ & $\times 4$ \\
$\mathrm{Sr}-\mathrm{O}(3)$ & $2.810(5)$ & $\times 8$ \\
$\mathrm{Ho}-\mathrm{O}(1)$ & $2.393(3)$ & $\times 2$ \\
$\mathrm{Cu}(1)-\mathrm{O}(1)$ & $1.91(4)$ & $\times 2$ \\
$\mathrm{Cu}\left(1^{\prime}\right)-\mathrm{O}\left(2^{\prime}\right)$ & $1.95(3)$ & $\times 1$ \\
$\mathrm{Cu}(2)-\mathrm{O}(1)$ & $2.272(9)$ & $\times 4$ \\
$\mathrm{Cu}(2)-\mathrm{O}(3)$ & $1.924(1)$ & \\
\hline
\end{tabular}

${ }^{a}$ Cations marked with ' are displaced by $(1 / 21 / 20)$ from the positions given in Table 1.

found for $\mathrm{Bi}$ in $\mathrm{Bi}_{2} \mathrm{Sr}_{2} \mathrm{CaCu}_{2} \mathrm{O}_{8}$, except that $\mathrm{Pb}^{2+}$ is fivecoordinated while $\mathrm{Bi}^{3+}$ is six-coordinated. ${ }^{5}$ Zandbergen $e t$ $a l .{ }^{3}$ claim that cleavage in these compounds occurs between the $\mathrm{PbO}$ and $\mathrm{SrO}$ planes. It is therefore surprising that the $\mathrm{Pb}-\mathrm{O}(1)$ distance is the shortest of the lead-oxygen distances.

The coordination of $\mathrm{Cu}(2)$ is similar to the coordination of $\mathrm{Cu}$ in the $\mathrm{CuO}_{2}$ layers in $\mathrm{YBa}_{2} \mathrm{Cu}_{3} \mathrm{O}_{7}$, except that the four $\mathrm{Cu}-\mathrm{O}$ bonds in the basal plane by symmetry are of equal length. The $\mathrm{Cu}-\mathrm{O}$ bond length in the basal plane is
1.924(1) $\AA$, and the $\mathrm{Cu}-\mathrm{O}$ bond perpendicular to the this plane is $2.272(2) \AA$. The corresponding values for $\mathrm{YBa}_{2} \mathrm{CuO}_{7}$ are $1.930(1)$ and 1.961(1) $\AA$ in the basal plane and 2.303(7) $\AA$ perpendicular to the basal plane. ${ }^{6}$

Half of the $\mathrm{Cu}(1)$ atoms are bonded to two $\mathrm{O}(2)$ atoms, while the other half are bonded to two $\mathrm{O}\left(2^{\prime}\right)$ atoms. The bond lengths for the two types of bonds are 1.909 and $1.952 \AA$, respectively. Despite the fact that the PbO layers are distorted, the presence of an inversion center in space group $P \overline{1}$ causes the two $\mathrm{Cu}-\mathrm{O}$ bonds to be collinear. Such a bonding scheme is found in several compounds containing $\mathrm{Cu}^{+}$, e.g. $\mathrm{Cu}_{2} \mathrm{O}, \mathrm{CuCrO}_{2}{ }^{7}$ and $\mathrm{YBa}_{2} \mathrm{Cu}_{3} \mathrm{O}_{6}{ }^{8}$ The $\mathrm{Cu}-\mathrm{O}$ bond lengths in these compounds are $1.841,1.85$ and 1.795(2) $\AA$, respectively. The $\mathrm{Cu}-\mathrm{O}$ bond lengths found in the title compound are longer than the corresponding bond lengths in the abovementioned compounds. This can presumably be explained by the fact that the "lone pair" electrons on the $\mathrm{Pb}$ atoms point towards the $\mathrm{Cu}$ layer.

It has been shown that compounds of this family can be oxidized at relatively low temperatures. ${ }^{1}$ The excess of oxygen atoms are believed to be located in the $\mathrm{Cu}$ layer. Therefore attempts were made during the initial refinements to find partially occupied oxygen sites in this layer. No indication of additional oxygen was found, which is a strong indication that the title compound contains eight oxygen atoms per formula unit.

Our neutron diffraction study of $\mathrm{Pb}_{2} \mathrm{Sr}_{2} \mathrm{HoCu}_{3} \mathrm{O}_{8}$ is in principle in agreement with the model proposed for $\mathrm{Pb}_{2} \mathrm{Sr}_{2} \mathrm{YCu}_{3} \mathrm{O}_{8}$ on the basis of powder neutron data by Cava et al. ${ }^{9}$ In this model the oxygen atoms in the $\mathrm{PbO}$ layers are statistically distributed around the $4 k$ position in the $\mathrm{Cmmm}$ space group. Our model describes the oxygen (a)

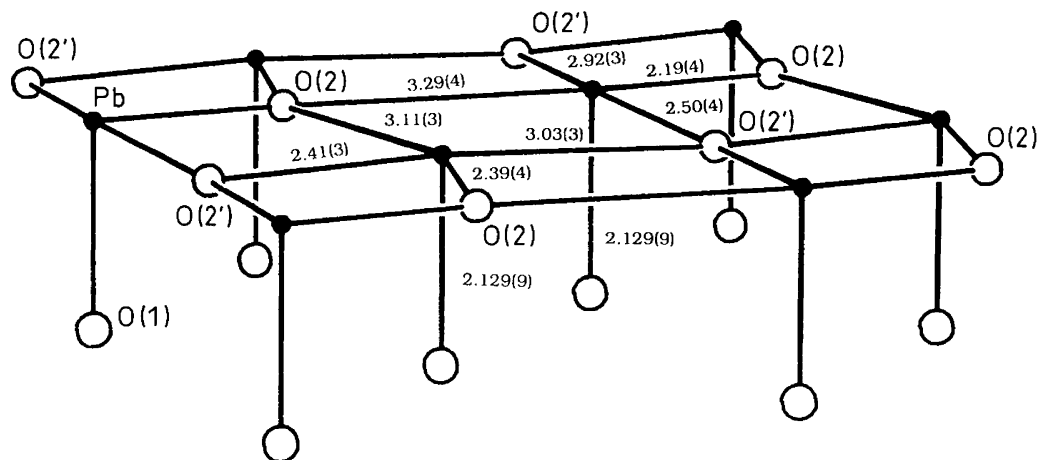

(b)

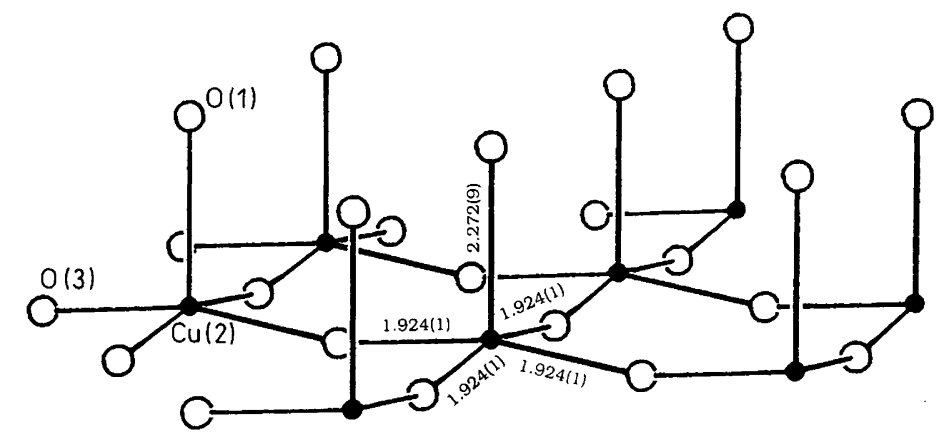

Fig. 3. Connectivity and relevant interatomic distances (in $\AA$ ) in the $\mathrm{PbO}$ layer (a) and the $\mathrm{CuO}_{2}$ layer (b) in $\mathrm{Pb}_{2} \mathrm{Sr}_{2} \mathrm{HoCu}_{3} \mathrm{O}_{8}$. The cations are marked with filled circles while the oxygen atoms are marked with open circles. The oxygen atoms below and above the lead and copper atoms in (a) and (b), respectively, are the $O(1)$ oxygen atoms. Oxygen atoms labelled $O(2), O\left(2^{\prime}\right)$ and $O(3)$ are located in the $\mathrm{PbO}$ and $\mathrm{CuO}_{2}$ layers, respectively. $\mathrm{Pb}$ is five-coordinated, with three short and two long $\mathrm{Pb}-\mathrm{O}$ bonds. $\mathrm{Cu}$ is also five-coordinated, with four short $\mathrm{Cu}-\mathrm{O}$ bonds of equal length in the basal plane and one longer $\mathrm{Cu}-\mathrm{O}$ bond perpendicular to the basal plane. 


\section{JøRGENSEN AND ANDERSEN}

atoms in the $\mathrm{PbO}$ layers as ordered and violating the $C$ centering. The ordering of these oxygen atoms is presumably the cause of the orthorhombic distortion of the unit cell. The model proposed here for the structure of the $\mathrm{PbO}$ layer is in qualitative agreement with the model proposed by Zandbergen $e t$ al. $^{3}$ on the basis of electron diffraction studies. However, we were unable to detect any displacements of the lead atoms. As seen from Table 2 the refinement gives no evidence for rotations of the $\mathrm{CuO}_{5}$ pyramids as proposed by Zandbergen et al. ${ }^{3}$ The temperature factors for the oxygen atoms in the $\mathrm{CuO}_{5}$ pyramids are of normal size.

Recently it has been shown that an orthorhombic-totetragonal phase transition occurs in $\mathrm{Pb}_{2} \mathrm{Sr}_{2} \mathrm{Y}_{0.5} \mathrm{Ca}_{0.5} \mathrm{Cu}_{3} \mathrm{O}_{8}$ around $750{ }^{\circ} \mathrm{C} .{ }^{10} \mathrm{~A}$ similar transition occurs in the title compound around $780^{\circ} \mathrm{C} .{ }^{11}$ This means that these compounds are formed in the tetragonal state during synthesis and are then transformed to the orthorhombic state during cooling. Annealing at temperatures around $700^{\circ} \mathrm{C}$ in a reducing (but oxygen-containing) atmosphere for longer times improves superconducting properties, while annealing above $800^{\circ} \mathrm{C}$ destroys superconductivity. ${ }^{10}$ These facts indicate that the orthorhombic distortion is of importance for the superconducting properties of these compounds. A full understanding of the influence of oxygen stochiometry and structural instability on superconductivity in this family of compounds has not yet been fully established.

Acknowledgement. The authors would like to thank the National Agency of Industry and Trade, Denmark for financial support of the $\mathrm{X}$-ray diffraction facilities used during the synthetic work.

\section{References}

1. Cava, R. J., Batlogg, B., Krajewski, J. J., Rupp, L. W., Jr., Schneemeyer, L. F., Siegrist, T., van Dover, R. B., Marsh, P., Peck, W. F., Jr., Gallagher, P. K., Glarum, S. H., Marshall, J. H., Farrow, R. C., Waszczak, J. V., Hull, R. and Trevor, P. Nature (London) 336 (1988) 211.

2. Wiles, D. B. and Young, R. A. J. Appl. Crystallogr. 14 (1981) 149.

3. Zandbergen, H. W., Kadowaki, K., Menken, M. J. V., Menovsky, A. A., van Tendoloo, G. and Amerlinckx, S. Physica C 158 (1989) 155

4. Brown, I. D. and Altermatt, D. Acta Crystallogr., Sect. B 41 (1985) 244.

5. Bordet, P., Capponi, J. J., Chaillout, C., Chenavas, J., Hewat, A. W., Hewat, E. A., Hodeau, J. L., Marezio, M., Tholence, J. L. and Tranqui, D. Physica C 156 (1988) 189.

6. Hewat, A. W., Capponi, J. J., Chaillout, C., Marezio, M. and Hewat, E. A. Solid State Commun. 64 (1987) 301.

7. Dannhauser, W. and Vaughan, P. A. J. Am. Chem. Soc. 77 (1955) 896; Neuburger, M. C. Z. Kristallogr. 77 (1931) 169.

8. Santoro, A., Miraglia, S., Beech, F., Sunshine, S. A., Murphy, D. W., Schneemeyer, L. F. and Waszczak, J. V. Mater. Res. Bull. 22 (1987) 1007.

9. Cava, R. J., Marezio, M., Krajewski, J. J., Peck, W. F., Jr., Santoro, A. and Beech, F. Physica C 157 (1989) 272.

10. Kadowaki, K.. Menken, M. J. and Moleman, A. C. Physica C 159 (1989) 165.

11. Jørgensen, J.-E. To be published.

Received May 15, 1990. 